\title{
Fruiting-body-base flour from an Oyster mushroom waste in the development of antioxidative chicken patty
}

\begin{abstract}
In a commercial oyster mushroom farm, from $300 \mathrm{~g}$ of the total harvest, only the cap and stem of the fruiting body parts are harvested (200 g) while the unused lower section called fruitingbody-base (FBB) is discarded $(50 \mathrm{~g})$. A new antioxidative FBB flour (FBBF) conversion to mixed-ratio chicken patty was recently developed which converts $16.67 \%$ of FBB into an edible flour. At the initial stage, pretreatments of FBBF were optimized at particle size $(106 \mu \mathrm{m})$ and citric acid concentration $(0.5 \mathrm{~g} / 100 \mathrm{~mL})$ to improve flour antioxidant responses. Such pretreatments boosted total phenolic content $(2.31 \pm 0.53 \mathrm{mg} \mathrm{GAE} / \mathrm{g})$ and DPPH $(51.53 \pm$ $1.51 \%)$ of pretreated FBBF. Mixed-ratio chicken patty containing FBBF (10\%, 20\%, 30\%) significantly $(\mathrm{P}<0.05)$ influenced the hardness, cohesiveness, springiness, and chewiness of the patties. However, only the hardness and chewiness increased proportionally with the increase FBBF in concentration. Notably, 60 panellists considered that $10 \%$ FBBF-chicken patty sensory attributes, including lightness, redness, and yellowness, is acceptable to consumers. This information could be used to market any type of commercial mushroom farm waste as alternative food products.
\end{abstract}

